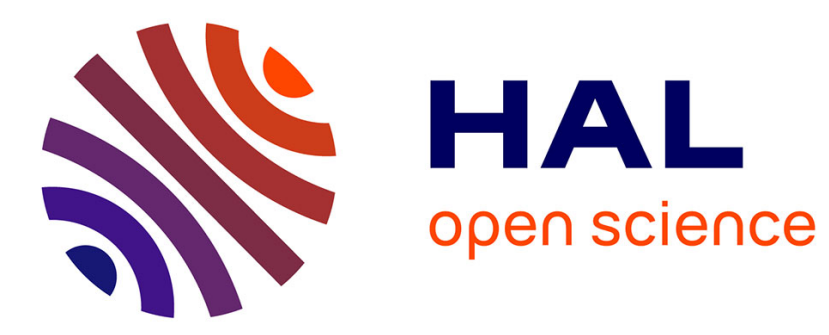

\title{
Neutral Genetic Drift-Based Engineering of a Sucrose-Utilizing Enzyme toward Glycodiversification
}

David Daudé, Alizée Vergès, Emmanuelle Cambon, Stéphane Emond, Samuel

Tranier, Isabelle André, Magali Remaud Simeon

\section{- To cite this version:}

David Daudé, Alizée Vergès, Emmanuelle Cambon, Stéphane Emond, Samuel Tranier, et al.. Neutral Genetic Drift-Based Engineering of a Sucrose-Utilizing Enzyme toward Glycodiversification. ACS Catalysis, 2019, 9 (2), pp.1241-1252. 10.1021/acscatal.8b03609 . hal-02177344

\section{HAL Id: hal-02177344 \\ https://hal.science/hal-02177344}

Submitted on 24 Nov 2020

HAL is a multi-disciplinary open access archive for the deposit and dissemination of scientific research documents, whether they are published or not. The documents may come from teaching and research institutions in France or abroad, or from public or private research centers.
L'archive ouverte pluridisciplinaire HAL, est destinée au dépôt et à la diffusion de documents scientifiques de niveau recherche, publiés ou non, émanant des établissements d'enseignement et de recherche français ou étrangers, des laboratoires publics ou privés. 


\title{
Neutral Genetic Drift-Based Engineering of a Sucrose-Utilizing Enzyme toward Glycodiversification
}

\author{
David Daudé, ${ }^{\dagger, \S}$ Alizée Vergès, ${ }^{\dagger, \S}$ Emmanuelle Cambon, ${ }^{\dagger}$ Stéphane Emond, ${ }^{\dagger}$ Samuel Tranier, ${ }^{\ddagger}$ \\ Isabelle André, $* \dagger+$ and Magali Remaud-Siméon*,† \\ †Laboratoire d’Ingénierie des Systèmes Biologiques et Procédés (LISBP), Université de Toulouse, CNRS, INRA, INSA, 135, avenue \\ de Rangueil, F-31077 cedex 04 Toulouse, France \\ ${ }^{\ddagger}$ Département Biophysique Structurale, Institut de Pharmacologie et de Biologie Structurale, Université de Toulouse, Université Paul \\ Sabatier, CNRS, F-31077 Toulouse, France
}

Supporting Information

\begin{abstract}
Neutral drift (also called purifying selection) is an attractive approach to generate polymorphic variant libraries for enzyme engineering. Here, we have applied this strategy to modify the substrate specificity of a transglucosylase. Our model enzyme, the amylosucrase from Neisseria polysaccharea, is a glucosylation biocatalyst of prime interest because it uses the widespread substrate sucrose as a glucosyl donor and shows broad acceptor promiscuity. A library of 440 functional amylosucrase variants was generated after four rounds of neutral drift at a low mutation rate. The functional variations present in this library were investigated by assaying the ability of these variants to use an alternative glucosyl donor ( $p$ nitrophenyl- $\alpha$-D-glucopyranoside, $p$ NP-Glc) and to glucosylate a range of acceptors (including methyl- $\alpha$-L-rhamnopyranoside, which is not naturally recognized by the parental enzyme). The impact of these mutations on the thermal stability of the variants was also assessed. Large variations of acceptor promiscuity were observed, ranging from the complete loss of detectable activity to a 2 -fold increase relative to the parental enzyme. Variants showing increased catalytic efficiency toward the alternative $p$ NP-Glc donor were also identified. Specifically, one variant combining four unprecedented amino acid changes was 25 -fold more efficient at utilizing $p$ NP-Glc than the parental enzyme and acquired glucosylation activity toward methyl- $\alpha$-L-rhamnopyranoside. Enzymes with improved thermal stability were also identified. Overall, our work demonstrates that neutral drift is an effective and powerful strategy to engineer transglycosylases with enhanced or even acquired substrate specificities from small-sized functional libraries compatible with accurate low-throughput multi-parameter analyses.
\end{abstract}

KEYWORDS: enzyme engineering, neutral drift, transglucosylase engineering, glycodiversification, amylosucrase

\section{INTRODUCTION}

Directed evolution has been extensively applied in the laboratory to mimic the Darwinian process of evolution in vitro through iterative cycles of gene diversification followed by selective screening to retain variants with desired properties. ${ }^{1-3}$ The success of this strategy, however, relies heavily on the development of efficient high-throughput screening (HTS) procedures for large variant libraries due to the extremely rare occurrence of beneficial mutations. ${ }^{4-7}$ In the past decade, powerful HTS tools have been described. ${ }^{8}$ However, the development of universal and miniaturized screening protocols allowing the simultaneous monitoring of diverse and nonrelated parameters remains critical for large library analysis. To circumvent such technical limitations, there is a growing interest in approaches allowing the generation of small-sized but high-quality enzyme libraries, compatible with lowthroughput and accurate functional assays. ${ }^{9-11}$ In particular, neutral genetic drift (named after Kimura's neutral theory of evolution; also dubbed purifying selections) is considered to be a powerful approach for building polymorphic libraries comprising variants with enhanced or novel characteristics. ${ }^{12}$ It is now largely assumed that neutral mutations, i.e., sequence changes occurring under selection pressure for maintaining the protein's original function, are essential to generate genetic polymorphism that may confer selective advantage under subsequent changing selection pressure. The groups of $\mathrm{F}$. Arnold and D. Tawfik first investigated the role of such nonadaptive neutral mutations in laboratory-driven evolution of promiscuous enzymes, demonstrating that the accumulation of amino acid changes that maintained enzymes' functional integrities largely modified their promiscuous activities. ${ }^{13-15}$ In subsequent works, the role of neutral mutations was further considered by subjecting the model protein TEM-1 $\beta$ lactamase to purifying selection at high mutational loads.

Received: September 7, 2018

Revised: December 11, 2018

Published: December 28, 2018 


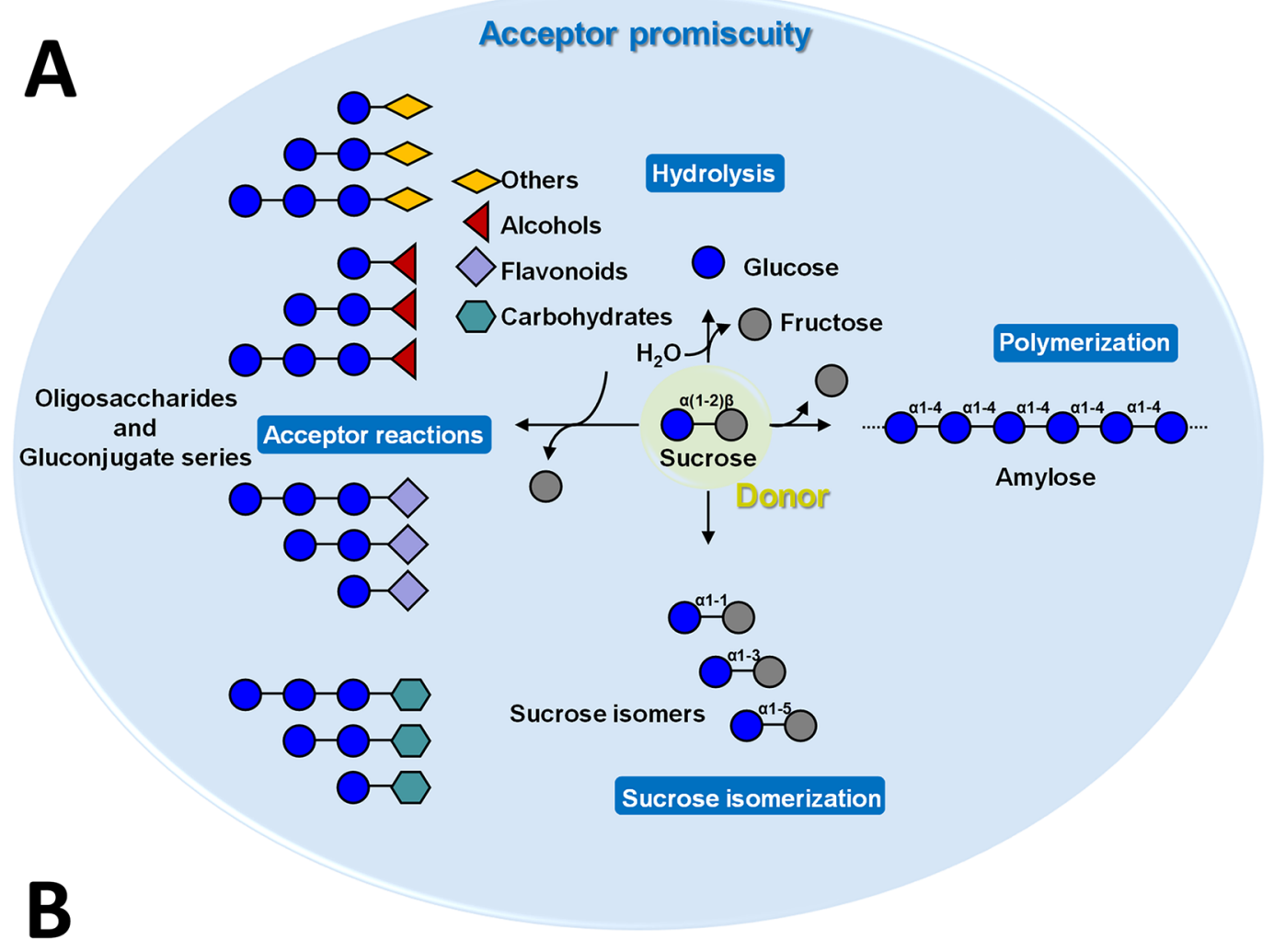

(a) Library construction

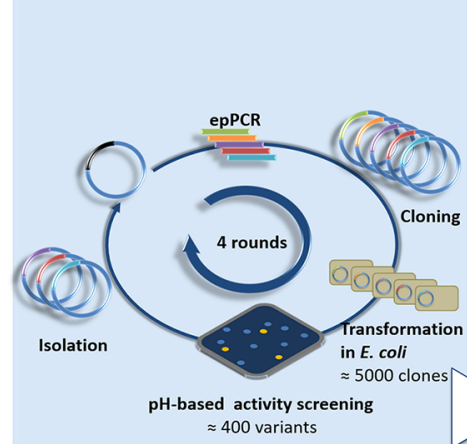

Neutral drift library (b) Screening library

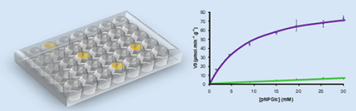

Activity assay and donor promiscuity

(Spectrophotometry analysis)

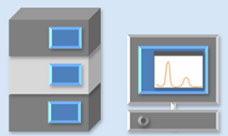

Probing acceptor promiscuity and search for new substrates (HPLC; MS)
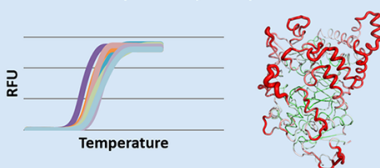

Determining stability of variants (Differential Scanning Fluorometry) (c) Sequence-structurefunction analysis
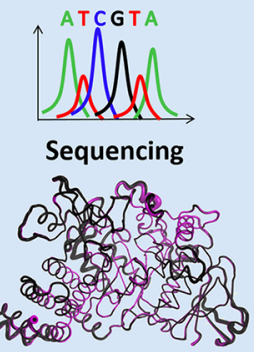

Crystallization

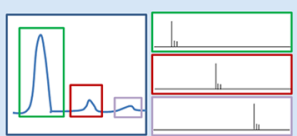

Product characterization (LC/MS)

Figure 1. Application of neutral drift to expand transglucosylation activities of amylosucrase. (A) Reactions catalyzed by $N p A S$ amylosucrase on sucrose in the presence or the absence of exogenous acceptors. (B) Overall engineering strategy: (a) generation of libraries of functional variants by neutral drift (i.e., repeated rounds of random mutagenesis followed by a $\mathrm{pH}$-based colony-screening assay to select active $\mathrm{NpAS}$ variants ${ }^{33}$; $(b)$ secondary activity and stability screening; and $(c)$ structure-function studies of the most improved transglucosylation variants.

These intense neutral drifts yielded variants with back-toconsensus/ancestor stabilizing mutations that in turn enabled the fixation of otherwise deleterious mutations. Mutations occurring under neutral drift can thus improve thermodynamic stability, yielding robust variants that may have selective advantages under changing environmental conditions. ${ }^{13}$ Moreover, neutral-drift-based investigations have provided experimental insights into the role of gradual genotype changes and the rise of new phenotypes in the course of evolution. ${ }^{16,17}$ The capacity of neutral variants to be further used as evolutionary starting points has also been investigated by shuffling neutrally evolved variants, leading to the identification of improved variants with increased promiscuous activities. ${ }^{18,19}$ Neutral genetic drift thus appears to be a powerful approach to identify superior starting points for protein engineering toward the selection of improved variants from small polymorphic libraries (i.e., containing on average $\leq 500$ variants). ${ }^{20}$

In the work described in the present Article, we investigated the potential of neutral drift to evolve and engineer a transglycosylase for the glycosylation of new acceptor 
substrates. Our model enzyme is the amylosucrase from Neisseria polysaccharea (NpAS), a member of glycosidehydrolase family 13 (GH13) according to the carbohydrateactive enzyme classification. ${ }^{2,23}$ This $\alpha$-transglycosylase uses sucrose ( $\alpha$-D-glucopyranosyl-1,2- $\beta$-D-fructofuranoside) as a glucosyl-donor substrate and catalyzes the formation of an amylose-like polymer with the concomitant release of fructose. $^{24,25} \mathrm{NpAS}$ can also glucosylate exogenous acceptors to synthesize various glycoconjugates (Figure 1A). Interestingly, while NpAS is strongly specific for sucrose (i.e., its natural donor substrate), its glucosylation activity toward acceptor substrates is highly promiscuous. ${ }^{26}$ This acceptor ambiguity is furthermore a highly evolvable feature of this enzyme, as previously demonstrated when engineering $N p A S$ for the synthesis of antigenic oligosaccharides, ${ }^{27-29}$ original disaccharides, ${ }^{30}$ maltooligosaccharides, ${ }^{31}$ or glucoconjugates. ${ }^{32}$ Here, we evaluated the potential of neutral drift to engineer a multipurpose transglucosylase. We generated a library of 440 functional NpAS variants after four rounds of neutral drift under low mutational load and examined the promiscuity profile of each variant using an alternative donor and various acceptors. Additionally, we investigated the effect on enzyme stability of the substitutions accumulated over the neutral drift experiment.

\section{RESULTS AND DISCUSSION}

Neutral Genetic Drift-Based Library. Our aim was to generate a library of functional variants from which enzymes with improved performances in terms of glycodiversification could be derived. As previously mentioned, NpAS is a transglucosylase showing naturally an interesting acceptor promiscuity due to the panel of acceptors that can be glucosylated by the wild-type (WT) enzyme (Figure 1A). We therefore subjected NpAS to four successive rounds of neutral drift (Figure 1B). Briefly, we randomly mutated the gene encoding NpAS by error-prone PCR at an average of 1.2 amino acids exchange per gene and, after cloning, screened the resulting library of around 5000 clones for activity toward sucrose. A previously reported $\mathrm{pH}$-based colony screening assay was used to purge deleterious mutations and identify variants retaining activity for sucrose cleavage. ${ }^{33}$ This screen exploits the ability of the colonies expressing an active amylosucrase variant to cleave sucrose and release fructose, which subsequently leads to medium acidification that is detectable with a chromogenic $\mathrm{pH}$ indicator. As such, it does not discriminate between glucoside-hydrolase and transglucosylase activities. Among the $N p A S$ variants deemed active at this step, we selected between 200 and 500 clones at random and subjected them to a further round of gene diversification and screening. This process was iterated four times, yielding $260,458,492$, and 440 functional NpAS variants after the first, second, third, and fourth rounds, respectively. After the fourth round, the enzymatic activities of crude cell extracts of the 440 selected variants were determined using a reducing sugar assay to measure sucrose cleavage ability and HPLC analysis to evaluate hydrolysis and transglucosylation levels. This analysis confirmed the retention of transglucosylation activity among all the variants selected in the fourth round (as reflected by the low proportion of released glucose and the presence of maltooligosaccharides on the HPLC profiles; data not shown).

The sucrose cleavage activity among the fourth round variants ranged between $10 \%$ and $350 \%$ of that of the parental NpAS (standard deviation (SD) $\sim 15 \%$ of its average activity; $n$
= 56). To address the importance of the strong specificity for sucrose in the context of the neutral drift experiment, we chose to differentiate two subsets of variants: (i) neutral variants with parent-like activity toward sucrose and (ii) nearly neutral variants with altered (i.e., enhanced or decreased) activity toward sucrose. Those variants that displayed sucrose cleavage activity within three standard deviations of the average activity of parental NpAS were considered as neutral, while those with activity levels outside the range of three standard deviations were defined as nearly neutral (Figure 2). This segregation was

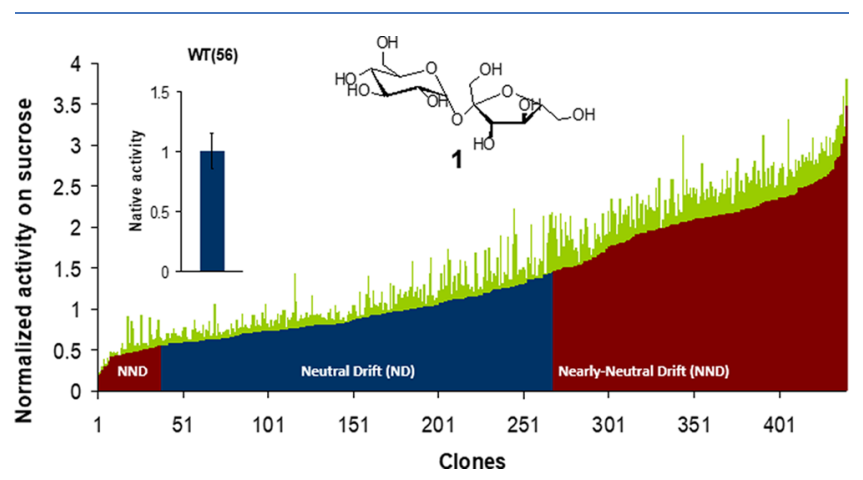

Figure 2. Relative activity of variants selected after the fourth round of neutral drift. Activities toward cleavage of sucrose (1) were determined in triplicate by measuring the release of reducing sugars in crude cell extracts over time and were normalized to the parental NpAS activity level (WT). Standard deviations (SD) for each variant are shown in green. For the parental enzyme, the calculated SD represents $15 \%$ of the average activity level $(n=56)$. Variants within 3SD of parental mean activity were arbitrarily defined as neutral (blue), and variants outside 3 SD were defined as nearly neutral (red).

established from the overall phenotypes of the variants as measured from their crude cell extracts, which does not take into account possible variation in expression levels. This arbitrary classification enabled the discrimination of two populations of variants with equivalent size (230 neutral variants and 210 nearly neutral variants), which are compared in this work.

To further characterize the mutational changes that occurred over the neutral drift experiment, we sequenced 100 neutral and 81 nearly neutral variants (representing $\sim 41 \%$ of the fourth round library). Overall, the sequenced variants were mutated at an average rate of $2.9 \pm 2.0$ nucleotide substitutions per variant (corresponding to $1.4 \pm 1.3$ amino acids exchanged per variant; Table 1). Nearly neutral variants harbored a slightly higher number of substitutions per variant than the neutral ones (1.6 versus 1.2 amino acid exchanges for the nearly neutral and the neutral variants, respectively). Fiftythree sequences $(29.3 \%$ of the sequenced variants) were found

Table 1. Sequence Analysis of Variants Selected after the Fourth Round of Neutral Drift

$\begin{array}{lcccc} & \begin{array}{c}\text { no. of } \\ \text { variants }\end{array} & \begin{array}{c}\text { no. of } \\ \text { sequenced } \\ \text { variants }\end{array} & \begin{array}{c}\text { average nucleotide } \\ \text { mutations per gene } \\ ( \pm S D)\end{array} & \begin{array}{c}\text { average amino } \\ \text { acid mutations per } \\ \text { gene }( \pm S D)\end{array} \\ \text { library } & 440 & 181 & 2.86( \pm 1.99) & 1.35( \pm 1.33) \\ \begin{array}{c}\text { neutral } \\ \text { variants }\end{array} & 230 & 100 & 2.76( \pm 1.83) & 1.18( \pm 1.34) \\ \begin{array}{c}\text { nearly } \\ \text { neutral } \\ \text { variants }\end{array} & 210 & 81 & 2.99( \pm 2.17) & 1.57( \pm 1.28) \\ & & & & \end{array}$



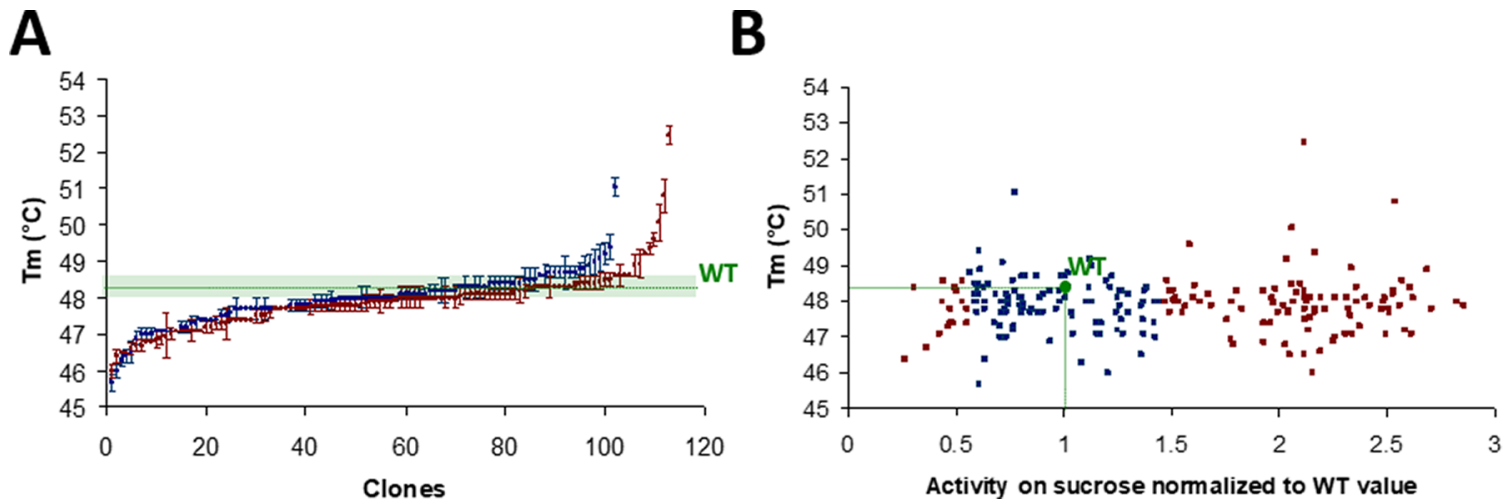

Figure 3. Thermostability of neutral and nearly neutral variants. (A) Changes in thermostability of neutral and nearly neutral variants. A total of 215 variants were randomly chosen from the fourth round of neutrally drifted variants, expressed in E. coli, and purified, and their melting temperatures $\left(T_{\mathrm{m}}\right)$ were measured in triplicate using differential scanning fluorimetry. (B) $T_{\mathrm{m}}$ values of neutral and nearly neutral variants plotted against the corresponding activity on sucrose.

to be identical to the parental enzyme at the protein level and $16(8.9 \%)$ had no mutations at all (i.e., the other 37 sequences displayed silent mutations). Overall, these sequencing data are in accordance with the fact that the neutral drift experiment was performed under low mutational load.

Effect on Stability of Neutral and Nearly Neutral Amino Acid Exchanges. Differential scanning fluorimetry (DSF) was used to measure the melting temperature $\left(T_{\mathrm{m}}\right)$ of 215 purified variants randomly chosen from the fourth round library (Figure $3 \mathrm{~A}$ ). The measured $T_{\mathrm{m}}$ values fell within a range of $7{ }^{\circ} \mathrm{C}$ (from 46 to $53{ }^{\circ} \mathrm{C}$ ) around the $T_{\mathrm{m}}$ of the parental enzyme $\left(\sim 48.4{ }^{\circ} \mathrm{C}\right)$ among both neutral and nearly neutral variants, demonstrating that the thermostability of the parent was marginally affected under the low mutational load of our neutral drift experiment. Interestingly, nearly neutral variants increased in both thermostability and activity toward sucrose cleavage were also identified (Figure 3B). Notably, a higher number of variants with increased stability were found in the upper part of the near-neutral library (among the more active crude extract). As previously mentioned, our arbitrary classification did not consider the possible variations of expression levels. Consequently, the more stable variants may be better expressed, as expression improvement is often correlated with enhanced stability.

Modulation of Native Enzyme Promiscuity. Toward Acceptor. NpAS has previously been shown to process a large range of exogenous molecules as acceptor substrates. Among them, alditols (e.g., xylitol, dulcitol, and myo-inositol) are glucosylated to various extents by the parental enzyme. ${ }^{22}$ Both neutral and nearly neutral variants selected from the fourth round of neutral drift (produced as crude cell extracts) were assayed toward these substrates, and the final conversion for each of the three acceptors was tested independently for each variant. Results for both populations were normalized to the conversion obtained with the parental enzyme (corresponding to $75 \%, 35 \%$, and $10 \%$, for xylitol, myo-inositol, and dulcitol, respectively) (Figure 4). Interestingly, both populations shared similar behavior in terms of maximum and range of acceptor conversion, indicating that acceptor glucosylation efficiency is not related to sucrose cleavage activity determined in the absence of acceptor. Up to 2 -fold increases in conversion rates were observed for myo-inositol and dulcitol. A relatively flat profile was obtained for xylitol conversion, and no significant improvement was observed, possibly because this substrate was already very well recognized by the parental enzyme (75\% conversion). Conversely, variants with impaired glucosylation capabilities toward the three substrates were also identified, indicating that neutral drift may also lead to the identification of variants with restricted promiscuity. Interestingly, glucosylation levels for the three tested acceptor molecules were altered differently among both neutral and nearly neutral variants (Figure 4D). Taken together, these observations demonstrate how neutral drift at a low mutational rate may lead to the generation of active variants with various functionalities, including many variants of interest with increased or restricted ability to convert polyols, some of them being highly specific for one polyol type.

Toward Donor. NpAS is highly specific for its natural donor substrate sucrose but possesses promiscuous activity toward a few alternative non-natural donors, including $\alpha$-fluoroglucoside and $p$-nitrophenyl- $\alpha$-D-glucopyranoside ( $p$ NP-Glc) ${ }^{26,34}$ In particular, we have previously reported that the kinetic parameters of $\mathrm{NpAS}$ were much lower for $p \mathrm{NP}$-Glc than for sucrose with up to 490 -fold decrease in $k_{\text {cat }} / K_{\mathrm{M}}$ for $p$ NP-Glc in comparison to sucrose in the same concentration range. ${ }^{26}$ To investigate whether neutral drift could yield variants with increased hydrolytic activity toward $p$ NP-Glc, we screened our fourth neutral drift round library of functional variants against that substrate. The variants were first purified using a miniaturized purification procedure ${ }^{35}$ to avoid background noise associated with the presence of $\alpha$-glycosidase activity of the host cell. Upon addition of $p$ NP-Glc, the donor consumption rate for each variant was determined by monitoring the absorbance at $405 \mathrm{~nm}$ of released $p$ nitrophenoxide. The resulting measured activities ranged from the limit of detection up to 9-fold improvement relative to the parental enzyme (Figure 5). Furthermore, the activities of neutral and nearly neutral variants showed similar distribution profiles as observed for acceptor glucosylation. Although no clear correlation could be established between the activities toward sucrose and $p \mathrm{NP}-\mathrm{Glc}$ under our experimental conditions, it is noteworthy that the two most improved variants against $p \mathrm{NP}$-Glc belonged to the neutral library, namely 7946C7 (V102M/S238T) and 7945E5 (D37H/ V331D/D526N/V609I). Moreover, the two best improved variants from the nearly neutral library, namely 7942D2 (N76S/S430L) and 7942F3 (A289T/K469R), were also increased by 2.5 -fold in their activity for sucrose and suggest 
A
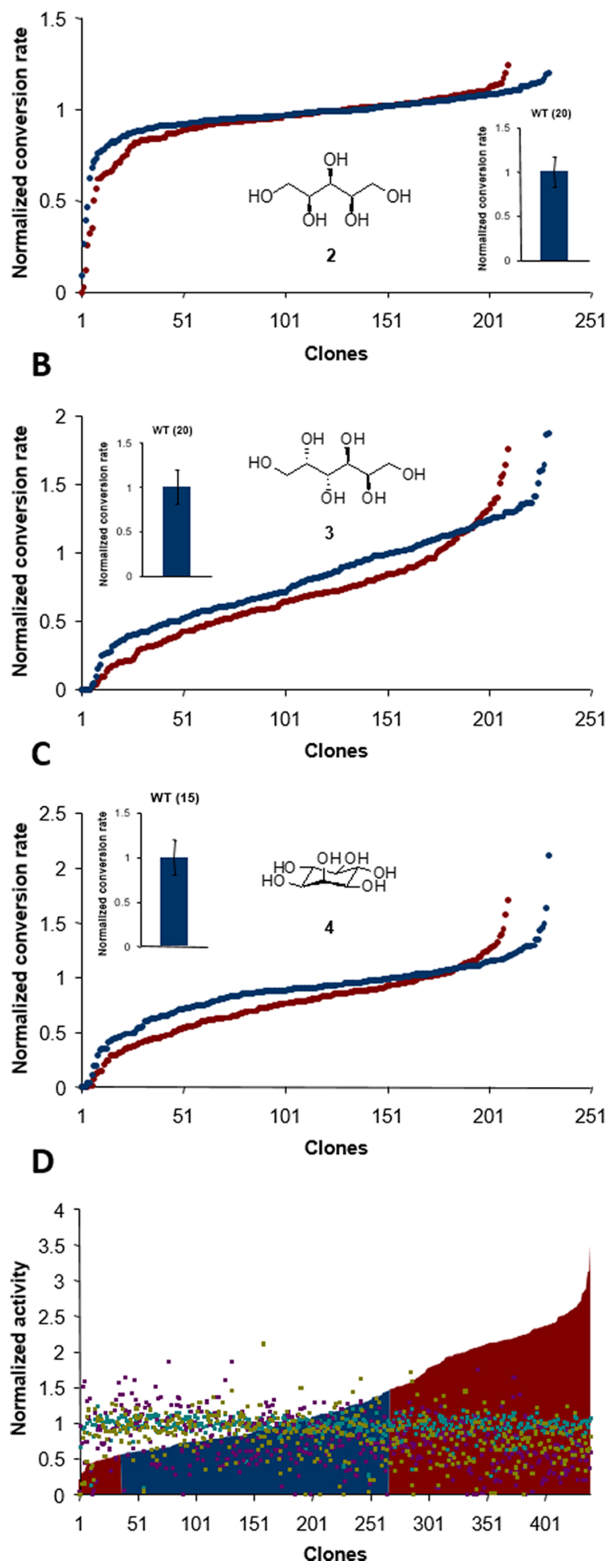

Figure 4. Acceptor promiscuity of $N p A S$ active variants after four rounds of neutral drift. The final conversion rates for alditols, namely (A) xylitol (2), (B) dulcitol (3), and (C) myo-inositol (4), using sucrose as donor were measured and normalized relative to the conversion rate of the parental enzyme. Replicate conversion rate measurements using parental NpAS were performed for each acceptor, with the number of repeats indicated in brackets. Conversion rates are represented in increasing order and further compared with respect to their corresponding sucrose activity, colored
Figure 4. continued

in cyan, purple, and olive green for 2,3 , and 4 , respectively (D). Neutral variants and nearly neutral variants are colored in blue and red, respectively.

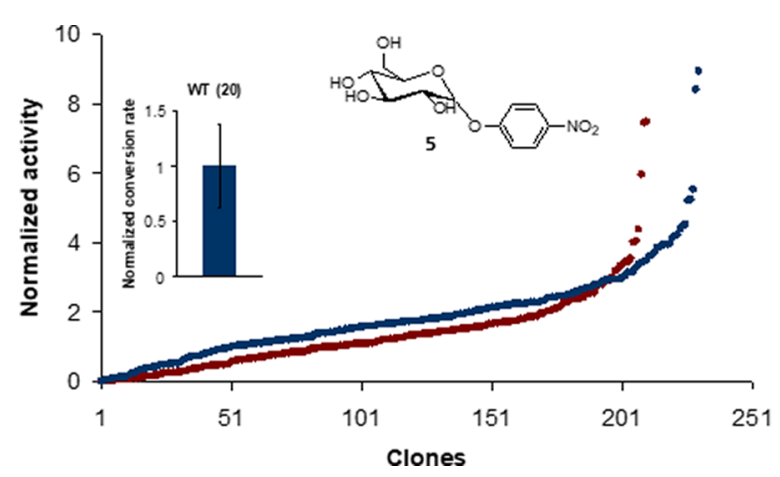

Figure 5. Donor promiscuity of $\mathrm{NpAS}$ active variants after four rounds of neutral drift. Purified variants were assayed toward the promiscuous substrate $p \mathrm{NP}-\mathrm{Glc}(5)$. The consumption rates were determined relative to the parental enzyme. Neutral and nearly neutral variants are indicated in blue and red, respectively. Variant activities are ranged in increasing order.

that these two activities are intrinsically associated. Among the improved variants against $p \mathrm{NP}-\mathrm{Glc}$, the melting temperature values were found similar to that of the parental enzyme except for 7945E5 that displayed the lowest thermodynamic stability out of the 440 variants.

Profiling of Drifted Variants. The amino acid substitutions are distributed throughout the $3 \mathrm{D}$ structure of $\mathrm{NpAS}$ (Figure 6). The enzyme's domains (e.g., A, B, and C domains common to the GH13 family and $\mathrm{N}$ and $\mathrm{B}^{\prime}$ amylosucrasespecific domains) all seem to be relatively tolerant to mutations (Figure 6A). Surprisingly, the $\mathrm{B}^{\prime}$ domain, which is involved in sucrose specificity, ${ }^{36}$ was more affected by neutral mutations than nearly neutral ones. Some substitutions are located on the enzyme surface and others are buried, indicating that neutral mutations are not necessarily distant from the active site. Moreover, highly conserved residues previously shown to be involved in sucrose ( $\mathrm{Y} 147 \mathrm{~F}$ in subsite -1 ) or acceptor (A289T, I330M, V331D in the first shell of subsite +1) recognition were also affected by substitutions. Analysis of sequence structure-function relationships was further considered for the most beneficial mutations (Figure $6 \mathrm{~B}$ and Table $\mathrm{S} 1$ ). The combination of substitutions $\mathrm{Y} 406 \mathrm{H}$ and A519T, as well as the S138T substitution, appeared to improve conversion rates toward the glucosylation of all three assayed acceptors.

Variants exhibiting a higher reactivity with $p$ NP-Glc contained more substitutions (from 2 to 4 ) on average. Substitution A289T, found in two distinct and highly efficient variants, and V331D are located in subsite +1 on flexible loops surrounding the NpAS active site. These substitutions, also deemed critical for non-natural acceptor glucosylation, are likely responsible for enhanced activity toward $p$ NP-Glc, possibly by helping with accommodation of the $p$ NP leaving group or promoting its release. ${ }^{27}$

With respect to stability improvement, a wide variety of mutations in terms of positions and number of substitutions (from 1 to 5) were observed, suggesting that combined mutations may act synergistically to improve the enzyme 
A

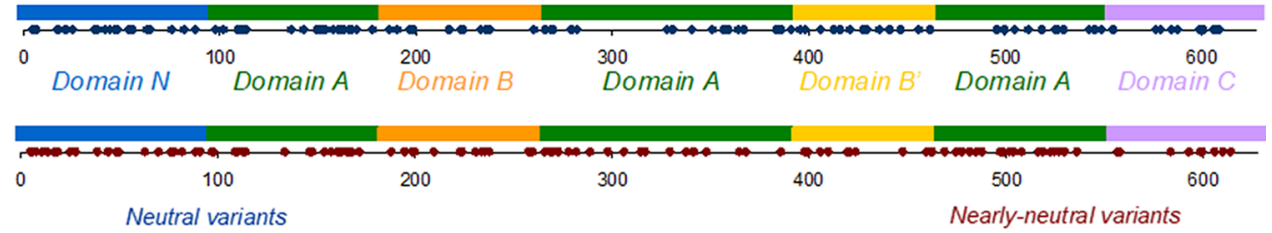
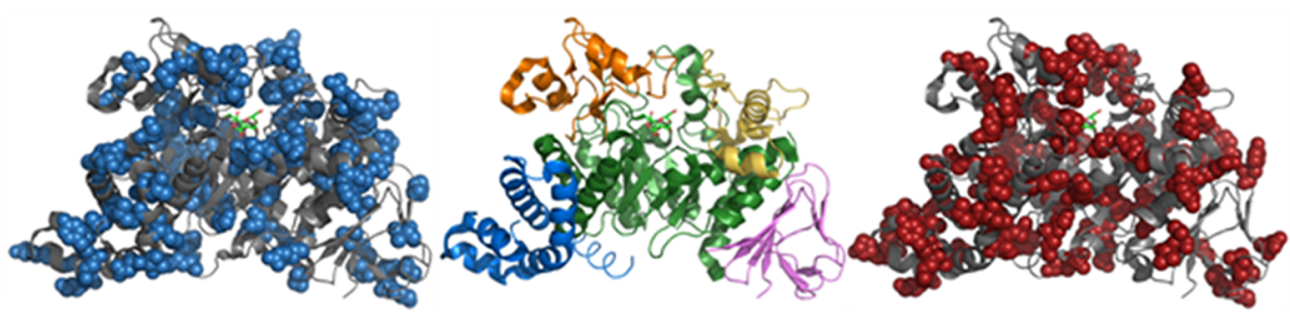

B

Xylitol

Dulcitol

Myo-inositol
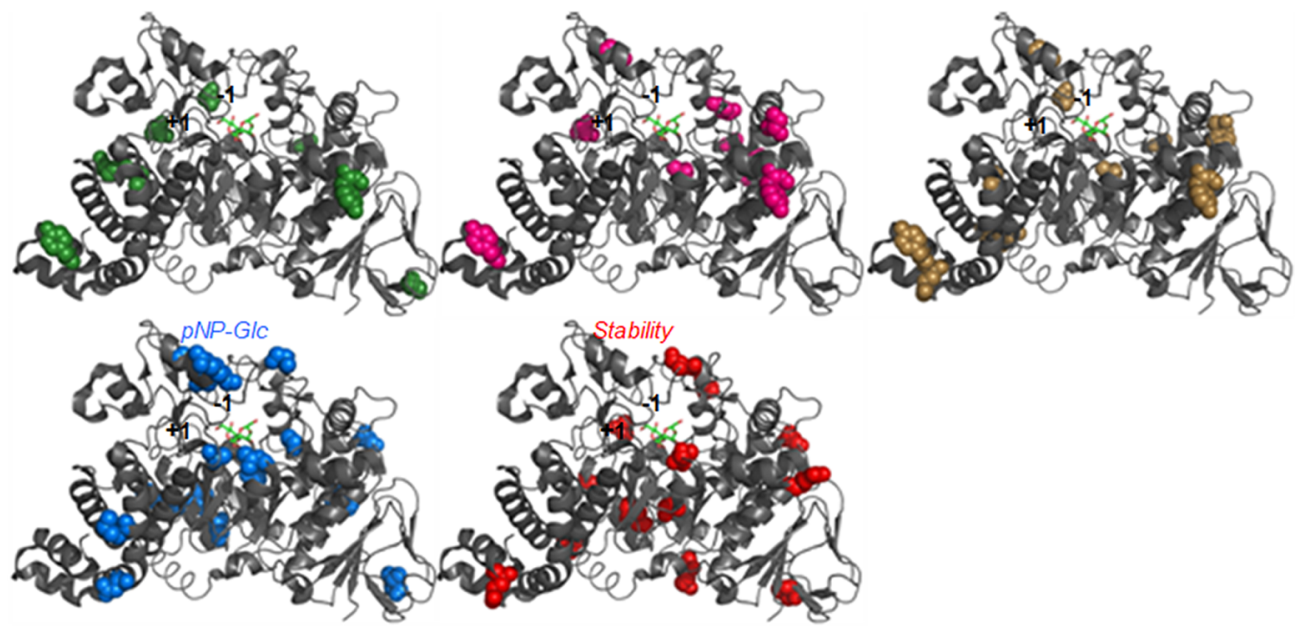

C

\begin{tabular}{|c|c|c|c|}
\hline \multirow[t]{16}{*}{ Acceptors } & \multirow[t]{5}{*}{ Xylitol } & $7942 \mathrm{G} 9$ & R143N/Y406H/A519T \\
\hline & & $7945 D 5$ & S151N \\
\hline & & 7945A1 & $\mathrm{R} 226 \mathrm{H}$ \\
\hline & & $7945 \mathrm{A3}$ & S610N \\
\hline & & $7945 A 11$ & N76S \\
\hline & \multirow[t]{5}{*}{ Dulcitol } & 7945D 5 & S151N \\
\hline & & $7945 \mathrm{A6}$ & S410N/Q523L \\
\hline & & $7946 C 7$ & V102M/S238T \\
\hline & & $7945 F 4$ & Y406H/A519T \\
\hline & & 7944E4 & Y6C/S448C \\
\hline & \multirow[t]{6}{*}{ Myo-inositol } & $7942 \mathrm{F9}$ & N76S/S430L \\
\hline & & $7946 C 7$ & $\mathrm{~V} 102 \mathrm{M} / \mathrm{S} 238 \mathrm{~T}$ \\
\hline & & $7942 \mathrm{G} 9$ & R143N/Y406H/A519T \\
\hline & & 794665 & $\mathrm{Q} 5 \mathrm{H}$ \\
\hline & & $7946 \mathrm{G} 6$ & K25N \\
\hline & & $7945 A 11$ & Y6C/A269V/A530T \\
\hline \multirow[t]{6}{*}{ Donor } & \multirow[t]{6}{*}{$p$ NP-Glc } & $7942 D 2$ & M44I/R223C/A289T \\
\hline & & $7942 \mathrm{~F} 3$ & A289T/K469R \\
\hline & & $7945 E 5$ & D37H/V331D/D 526N/V6091 \\
\hline & & $7946 C 7$ & V102M/S238T \\
\hline & & $7944 G 4$ & R166H/V168l/D460E \\
\hline & & $7943 E 10$ & S178T/G236C/G396S/S441N \\
\hline \multirow{5}{*}{\multicolumn{2}{|c|}{ Stability }} & 7946E10 & Q.5R/D231N/I330M/G348S \\
\hline & & $7946 \mathrm{~B} 7$ & E365D/D 460E \\
\hline & & $7942 \mathrm{D} 9$ & K97E/A158T/G163R/I282V/D 497V \\
\hline & & 7944D 11 & N76S \\
\hline & & $7944 E 3$ & $1282 \mathrm{~V} / \mathrm{H} 601 \mathrm{P}$ \\
\hline
\end{tabular}

Figure 6. Sequence structure-function analysis of variants. (A) Localization of neutral (blue spheres) and nearly neutral (red spheres) substitutions on the NpAS structural domains (PDB code: 1JGI). (B) Representation of all substitutions harbored by improved variants toward xylitol (green), dulcitol (magenta), myo-inositol (yellow), pNP-Glc (blue), and stability (red). (C) Amino acid substitution in improved variants. 

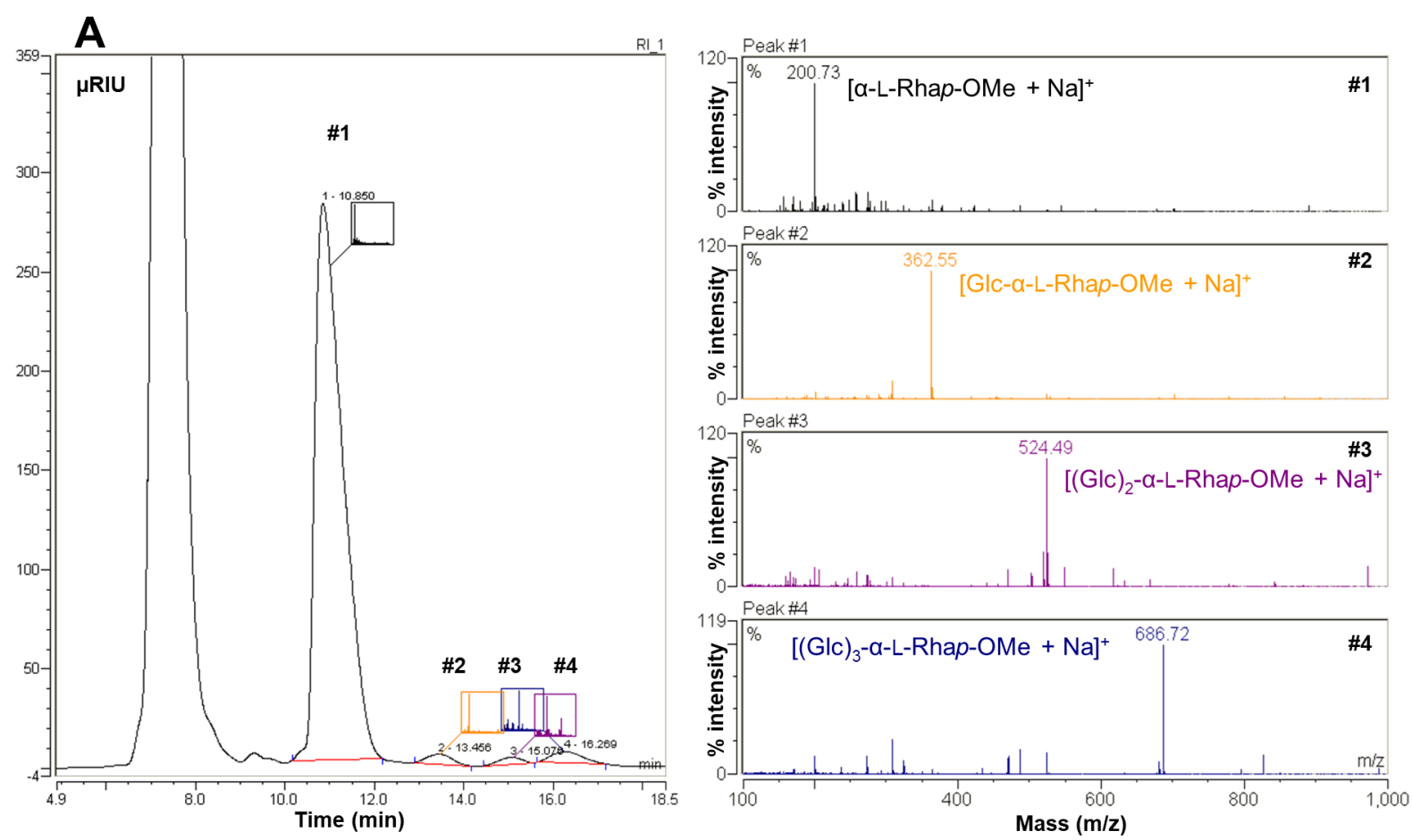

B

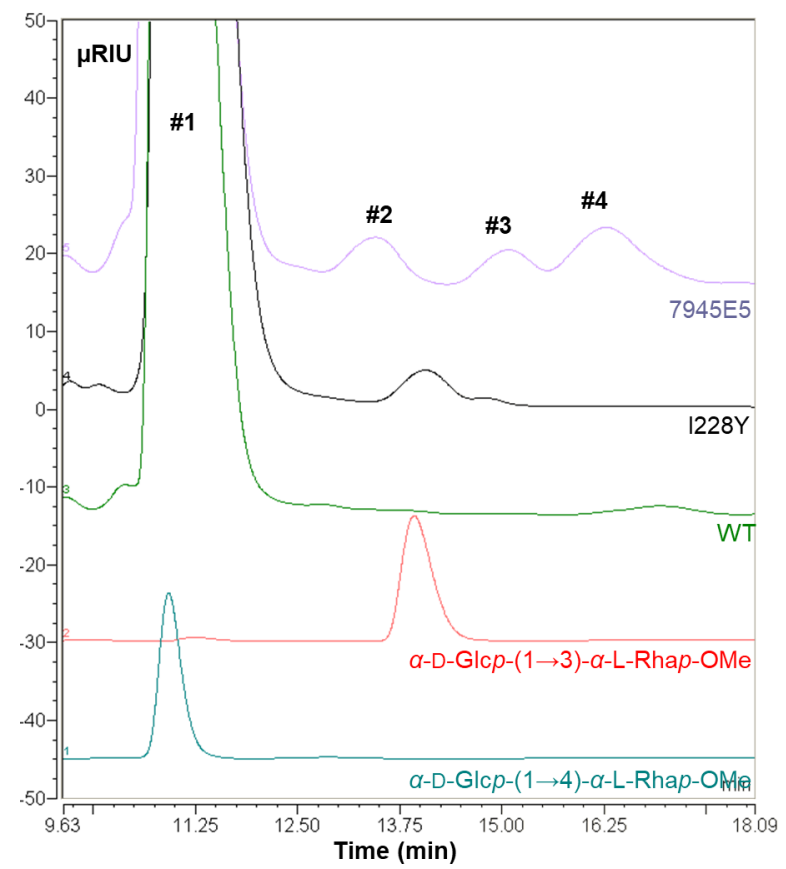

Figure 7. Neutral drift variant 7945E5 displays new acceptor activity toward $\alpha$-L-Rhap-OMe. (A) LC/MS analyses were performed to determine the molar mass of the glucosylation products obtained with variant 7945E5. (B) The structure of the monoglucosylated product was deduced from comparisons with chemically and enzymatically synthesized standards, namely $\alpha$-D-glucopyranosyl-(1 $\rightarrow 3)$ - $\alpha$-L-rhamnopyranoside and $\alpha$-Dglucopyranosyl-( $1 \rightarrow 4)$ - $\alpha$-L-rhamnopyranoside.

thermostability. The highest $T_{\mathrm{m}}$ value was observed for a variant harboring four amino-acid substitutions (7946E10: Q5R/D231N/I330M/G348S) with a $4{ }^{\circ} \mathrm{C}$ increase in $T_{m}$ compared to the parent enzyme.

Search for Novel Specificity. The results described thus far emphasize how neutral and nearly neutral mutations can significantly affect $N p A S$ substrate promiscuity. Next, we investigated whether neutral drift could yield variants with improved glucosylation activity on a non-natural acceptor of interest, methyl- $\alpha$-L-rhamnopyranoside ( $\alpha$-L-Rhap-OMe), one of the sole reported monosaccharide non-naturally used as an acceptor by the WT enzyme. Glucosylation products of this monosaccharide are key intermediates toward the synthesis of Shigella flexneri antigens. We previously developed a computeraided enzyme engineering approach to generate NpAS variants able to glucosylate this monosaccharide. ${ }^{27-29}$ This work led to the identification of a single-substitution variant (I228Y) which

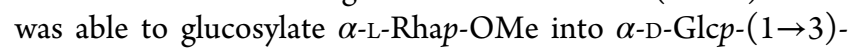


B
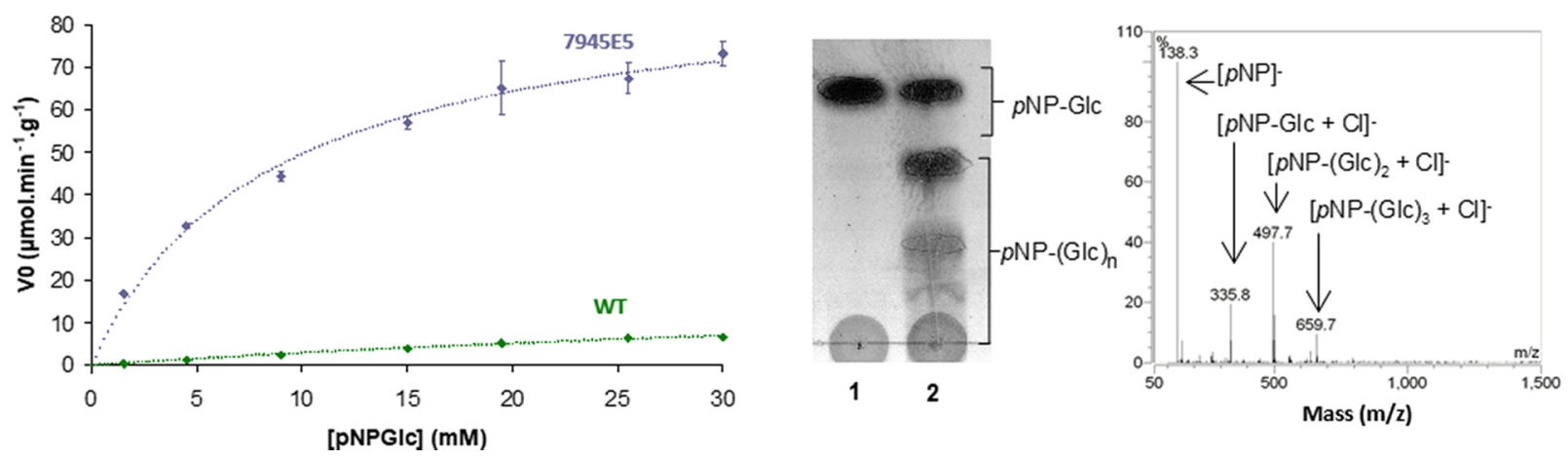

Figure 8. Activity of variant 7945E5 toward pNP-Glc. (A) Michaelis-Menten plot for parental NpAS and variant 7945E5. (B) MS and TLC analyses of transglucosylation capacity of variant 7945E5 when $p$ NP-Glc was used as sole substrate.

$\alpha$-L-Rhap-OMe. ${ }^{33}$ Here, we evaluated the capacity of the drifted variants to catalyze reaction of $\alpha$-L-Rhap-OMe with no prior structural design.

Surprisingly, we detected one variant in the fourth-round neutral library (7945E5: D37H/V331D/D526N/V609I) which had acquired the ability to glucosylate $\alpha$-L-Rhap-OMe. HPLC/MS analyses further enabled the detection of three different products corresponding to mono-, di-, and triglucosylated products (Figure 7A). Interestingly, the retention time of the monoglucosylated form was clearly

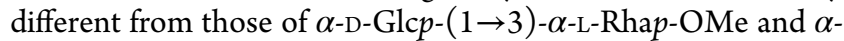
D-Glcp-(1 $\rightarrow 4)-\alpha$-L-Rhap-OMe (Figure 7B), indicating that variant $7945 \mathrm{E} 5$ catalyzed the synthesis of an unprecedented glucosylation product never previously obtained using NpAS variants. Unfortunately, the precise structure of this product could not be determined within the scope of the present work due to poor reaction yields and hence insufficient isolable material for NMR characterization. Nevertheless, given that $\alpha$ L-Rhap-OMe harbors only three hydroxyl groups (at positions $\mathrm{C}-2$, C-3, and C-4), we may reasonably assume it to be $\alpha$-Dglucopyranosyl-( $1 \rightarrow 2)$ - $\alpha$-L-rhamnopyranoside, a molecule not currently recorded as enzymatically produced in nature. It is noteworthy that this motif is part of the repeating unit of the Escherichia coli $\mathrm{O} 13 \mathrm{O}$-antigen. ${ }^{37}$ Overall, this preliminary result demonstrates the utility/potential of neutral drift to open access to novel enzyme activities by yielding superior alternative starting points for further protein engineering.

Characterization of 7945E5 Variant Showing a Novel Specificity. Structural Analysis. To obtain further insight on how acceptor specificity was changed, the X-ray structure of the variant 7945E5 was determined at a resolution of $1.60 \AA$ resolution (Table S2, PDB code: 5N6V). With a rmsd calculated on $628 \mathrm{C} \alpha$ atoms of $0.25 \AA$, the structure is highly similar to that of the WT NpAS (PDB code: 1G5A). ${ }^{36}$ As often observed in NpAS crystal structures, a Tris molecule was found in the active site $28,30,36$ despite the fact that the crystals were soaked in $100 \mathrm{mM} \alpha$-L-Rhap-OMe and sucrose. Crystallographic data also revealed the presence of other ligands in the structure (Figure S1): two sucrose molecules bound in SB2 and SB3 binding sites previously described, ${ }^{38,39}$ and two fructose molecules found in a binding site that we named SB5, corresponding to the previously identified oligosaccharide binding site OB3. Both SB3 and SB5 sites are located at the enzyme surface. SB5 is also positioned at the interface between two-symmetry-related molecules. A glucose molecule was also found bound in OB2 site. Regarding the role of the introduced mutations, three positions (i.e., 37, 526, and 609) are remote from the active site and not in direct contact with the product (Figure S2). Position 331 is located in the +1 subsite and was investigated by saturation mutagenesis in previous work. ${ }^{27}$ However, none of the corresponding single variants were able to glucosylate $\alpha$-L-Rhap-OMe. ${ }^{33}$ This observation clearly indicates that the additional substitutions at positions 37, 526 , and 609 of variant $7945 \mathrm{E} 5$ are key in the acquisition of the new acceptor specificity. Such a variant would not have been designed by rational or even semi-rational engineering approaches as the combinatorial effects of amino acid changes is difficult to predict, especially when involving residues far from the active site. These results further demonstrate that neutral genetic drift is a powerful strategy for generating enzyme variants with original combinations of amino acid substitutions and unprecedented catalytic capabilities.

Increased Activity toward pNP-Glc. Interestingly, variant $7945 E 5$ also displayed increased activity on $p$ NP-Glc (7-fold increase over parental NpAS under screening conditions). The kinetic parameters of this variant toward $p$ NP-Glc revealed a 25 -fold increase in catalytic efficiency $\left(k_{\text {cat }} / K_{\mathrm{M}}\right)$ compared to the parental enzyme (Figure 8A, Table 2). Thin-layer

Table 2. Kinetic Parameters toward $p$ NP-Glc and $T_{\mathrm{m}}$ Values of 7945E5 and NpAS Enzymes

\begin{tabular}{|c|c|c|}
\hline & NpAS & variant $7945 \mathrm{E} 5$ \\
\hline \multicolumn{3}{|c|}{ Kinetic Parameters } \\
\hline$K_{\mathrm{M}}(\mathrm{mM})$ & $66.9^{a}$ & 8.5 \\
\hline$k_{\text {cat }}\left(\min ^{-1}\right)$ & 1.6 & 6.5 \\
\hline$V_{\mathrm{M}}\left(\mu \mathrm{mol}\right.$ product released $\left.\cdot \mathrm{min}^{-1} \cdot \mathrm{g}^{-1}\right)$ & $22.3^{a}$ & 91 \\
\hline$k_{\text {cat }} / K_{\mathrm{M}}\left(\mathrm{mM}^{-1} \cdot \mathrm{min}^{-1}\right)$ & $0.03^{a}$ & 0.76 \\
\hline \multicolumn{3}{|c|}{ Thermostability } \\
\hline$T_{\mathrm{m}, \mathrm{DSF}}\left({ }^{\circ} \mathrm{C}\right)$ & 48.4 & 45.7 \\
\hline$T_{\mathrm{m}, \mathrm{CD}}\left({ }^{\circ} \mathrm{C}\right)$ & 48.1 & 45.7 \\
\hline
\end{tabular}

chromatography (TLC) and mass spectrometry (MS) revealed that $p$ NP-Glc acts as both donor and acceptor substrate during the transglucosylation reaction (Figure $8 \mathrm{~B}$ ). It is noteworthy that variant $7945 \mathrm{E} 5$ had the lowest $T_{\mathrm{m}}$ value among the 215 variants evaluated by DSF ( $T_{\mathrm{m}}$ decreased by $3{ }^{\circ} \mathrm{C}$ compared to parental $N p A S$ ), which was further confirmed by circular 
dichroism (CD) (Table 2). Analysis of the average B-factors suggested that loop 8 (residues 495-502) is more flexible in variant 7945E5 in comparison to parental NpAS (Figure S3). This observation is in agreement with previous conclusions stating that substitutions affecting functionality (e.g., substrate specificity) are often detrimental to protein stability. ${ }^{28,40,41}$

\section{CONCLUSIONS}

In the present Article, we describe a low mutational rate neutral-drift engineering approach applied to a sucroseutilizing transglycosylase, amylosucrase from Neisseria polysaccharea. Four repeated rounds of random mutagenesis and purifying selection were performed, yielding a library of 440 functional enzyme variants with parent-level activity on sucrose. The introduced neutral variations $(1.4 \pm 1.3$ amino acid exchange per variant) did not affect overall protein stability, as only marginal variations in thermostability $( \pm 3.5$ ${ }^{\circ} \mathrm{C}$ around the $T_{\mathrm{m}}$ of the parent) were recorded among the variants. Extensive screening revealed large variations in the neutrally drifted population for both donor and acceptor reactions. Analysis of the final conversion rates for three polyol acceptors revealed variations spanning from activity loss (below detectable levels) to a 2 -fold increase relative to the parent enzyme. Additionally, activity toward the promiscuous donor $p$ NP-Glc also fluctuated significantly among the variants, with a 25 -fold improvement in catalytic efficiency $\left(k_{\text {cat }} / K_{\mathrm{m}}\right)$ observed for a neutral variant harboring four amino acid substitutions (namely 7945E5: D37H/V331D/D526N/ V609I). Moreover, this variant also showed transglucosylation activity toward a new acceptor, methyl- $\alpha$-L-rhamnopyranoside, which is a precursor of prime interest for the synthesis of antigenic oligosaccharides from Shigella flexneri and Escherichia coli. Interestingly, this nearly neutral variant was also the least stable variant $\left(T_{\mathrm{m}} \approx 45.7^{\circ} \mathrm{C}\right)$ recorded among the neutrally drifted population. Altogether, these results further demonstrate that neutral drift may help to enlarge the substrate scope of enzymes while maintaining their natural functional integrity. Our data also demonstrate that this approach is very effective for identifying biocatalysts with enhanced or even new catalytic properties by evolving small-sized libraries compatible with low-throughput but accurate analyses. The combined effects on catalytic activity, substrate conversion rate, and thermostability further suggest that neutral drift can be a powerful enzyme engineering strategy for synthetic biology. The use of such neutral and polymorphic libraries can lead to the generation of finely tuned variants with modified properties that have proven essential for balancing new enzymatic pathways.

\section{EXPERIMENTAL AND THEORETICAL PROCEDURES}

Bacteria, Plasmid, Strain, and Chemicals. Plasmid pGST-AS derived from the pGEX-6P-3 vector (GE Healthcare Biosciences) and containing the gene encoding amylosucrase from Neisseria polysaccharea amylosucrase (NpAS) was used as the template for the construction of saturation mutagenesis libraries. Escherichia coli Top 10 was used as the host strain for plasmid transformation and gene expression. Sucrose was purchased from Merck KGaA (Darmstadt, Germany). Xylitol, myo-inositol, dulcitol, $p$-nitrophenyl- $\alpha$-D-glucopyranoside, glutathione reduced, dithiothreitol, bromothymol blue (BTB), and lysozyme were purchased from Sigma-Aldrich (St. Louis, MO, USA). Methyl- $\alpha$-L-rhamnopyranoside, methyl- $\alpha$-D-gluco- pyranosyl-( $1 \rightarrow 3)-\alpha$-L-rhamnopyranoside, and $\alpha$-D-glucopyranosyl-( $1 \rightarrow 4)-\alpha$-L-rhamnopyranoside were chemically synthesized and characterized at the Unité de Chimie des Biomolécules, Institut Pasteur, France. ${ }^{27,42}$ Ampicillin, isopropyl $\beta$-D-thiogalactopyranoside (IPTG), and deoxyribonuclease I were purchased from Euromedex (Souffelweyersheim, France). DpnI, EcoRI HF, and NotI HF restriction enzymes, T4 DNA ligase, and Antarctic Phosphatase were purchased from New England Biolabs (Beverly, MA, USA). Oligonucleotides were synthesized by Eurogentec (Liege, Belgium). DNA extraction (GenElute HP plasmid Miniprep) and purification (GenElute Gel Extraction) kits were purchased from SigmaAldrich.

Construction, Selection, and Expression of Variant Library. Mutations were introduced randomly by error-prone PCR using the GeneMorph II Random Mutagenesis kit (Agilent Technology) according to the manufacturer's instructions, with pGST-AS (350 $\mathrm{ng}$ ) as vector template for the first round of mutagenesis. PCR amplifications were carried out with Mutazyme II DNA polymerase $(2.5 \mathrm{U})$. The cycling included a denaturation step at $95{ }^{\circ} \mathrm{C}(2 \mathrm{~min})$ and then 30 cycles composed of (i) a denaturation step at $95^{\circ} \mathrm{C}(30 \mathrm{~s})$, (ii) a hybridization step at $55{ }^{\circ} \mathrm{C}(30 \mathrm{~s})$, and (iii) an elongation step at $72{ }^{\circ} \mathrm{C}(4 \mathrm{~min})$. A final elongation step at $72{ }^{\circ} \mathrm{C}(10$ min) was performed. DNA was digested with $D p n \mathrm{I}$ and further purified. The pool of genes was then double-digested by EcoRI HF and NotI HF restriction enzymes and gel purified. In parallel, a cloning vector was prepared by double-digesting the pGST-AS with EcoRI HF and NotI HF restriction enzymes, followed by dephosphorylation with Antarctic Phosphatase and gel purification following the manufacturer's recommendations. Insert (50 $\mathrm{ng}$ ) and vector (50 ng) were ligated using T4 DNA ligase $\left(10 \mathrm{~min} ; 25^{\circ} \mathrm{C}\right)$. The ligation product was precipitated with 5 volumes of absolute ethanol and $1 / 10$ volume of sodium acetate ( $3 \mathrm{M} ; \mathrm{pH} 5.3)$ at $-20{ }^{\circ} \mathrm{C}$ overnight. DNA was centrifuged $\left(30 \mathrm{~min}, 18000 \mathrm{~g}, 4^{\circ} \mathrm{C}\right)$, and the pellet was rinsed two times with $70 \%$ ethanol and dried under vacuum using an Eppendorf concentrator 5301. The pellet was resuspended in water, and $2 \mu \mathrm{L}$ was used to transform $50 \mu \mathrm{L}$ of E. coli Top 10 electro-competent cells before plating on LB agar plates supplemented with $1 \%$ glycerol and $100 \mu \mathrm{g} \cdot \mathrm{mL}^{-1}$ ampicillin on which a hydrophilic membrane (Durapore membrane filter, $0.22 \mu \mathrm{m}$, Millipore) had been overlaid. After $24 \mathrm{~h}$ at $37^{\circ} \mathrm{C}$, the membrane was transferred onto another LB agar plate supplemented with ampicillin $(100 \mu \mathrm{g}$. $\left.\mathrm{mL}^{-1}\right)$, sucrose $(146 \mathrm{mM})$, IPTG $(1 \mathrm{mM})$, Tris buffer $(50$ $\mathrm{mM}, \mathrm{pH} 7.5)$, and BTB indicator $\left(0.1 \mathrm{~g} \cdot \mathrm{L}^{-1}\right)$ and incubated for $24 \mathrm{~h}$ at $30{ }^{\circ} \mathrm{C}$ as previously described. ${ }^{33} \mathrm{~A}$ library of around 5000 recombinant clones was obtained. Cells expressing amylosucrase variants still active on sucrose were colored yellow and thus easily differentiated, and 260 clones were picked at random and transferred into 96-well microplates, containing in each well $200 \mu \mathrm{L}$ of $2 \mathrm{XYT}$ medium supplemented with $100 \mu \mathrm{g} \cdot \mathrm{mL}^{-1}$ ampicillin. After $24 \mathrm{~h}$ of incubation at $30{ }^{\circ} \mathrm{C}$, the variants were plated on $\mathrm{LB}$ agar supplemented with $100 \mu \mathrm{g} \cdot \mathrm{mL}^{-1}$ ampicillin. The clones were grown overnight at $37^{\circ} \mathrm{C}$, and the colonies were scraped from the plate for plasmid extraction, constituting the first-round library. This plasmid pool was used as the template for the second round of mutagenesis following the procedure outlined above. Altogether, four rounds of mutagenesis were performed. Finally, 260, 458, 492, and 440 variants were selected from 
libraries of around 5000 clones after the first, second, third, and fourth rounds, respectively.

Microplate Purification Protocol. This previously described protocol ${ }^{35}$ was applied here to purify variants grown individually in microplate wells. Storage microplates containing the neutral-drift library were thawed and replicated to inoculate starter culture in 96-well microplates containing in each well $200 \mu \mathrm{L}$ of LB medium supplemented with $100 \mu \mathrm{g}$. $\mathrm{mL}^{-1}$ ampicillin. After growth for $12 \mathrm{~h}$ at $30{ }^{\circ} \mathrm{C}(700 \mathrm{rpm})$, plates were duplicated four times into 96-Deep Well plates containing in each well, $1 \mathrm{~mL}$ LB medium supplemented with $100 \mu \mathrm{g} \cdot \mathrm{mL}^{-1}$ ampicillin. Cultures were then grown for $24 \mathrm{~h}$ at $23{ }^{\circ} \mathrm{C}$ (700 rpm), and IPTG was added (to a final concentration of $1 \mathrm{mM}$ ) to induce glutathione S-transferaseamylosucrase variant fusion protein expression. After 6 to $8 \mathrm{~h}$, plates were centrifuged $\left(20 \mathrm{~min}, 3000 \mathrm{~g}, 4{ }^{\circ} \mathrm{C}\right)$, and the supernatant was removed. The cell pellet was resuspended in $200 \mu \mathrm{L}$ of phosphate-buffered saline (PBS) $2 \mathrm{X}(\mathrm{pH} 7.3$, containing lysozyme $0.5 \mathrm{mg} \cdot \mathrm{mL}^{-1}$ and $1.5 \mathrm{U}$ of deoxyribonuclease I) followed by freezing at $-80{ }^{\circ} \mathrm{C}$ for $8-12 \mathrm{~h}$. After thawing at room temperature, the plates were centrifuged (20 min, $3000 g, 4{ }^{\circ} \mathrm{C}$ ), and $150 \mu \mathrm{L}$ portions of each the four supernatants were transferred to a single GST MultiTrap 4B (GE Healthcare Biosciences) 96-well plate $(600 \mu \mathrm{L}$ of supernatant per well). Unbound proteins were removed by centrifugation $\left(4 \mathrm{~min}, 100 g, 4{ }^{\circ} \mathrm{C}\right)$. PBS $(600 \mu \mathrm{L})$ was added to each well to wash bound samples, and this operation was repeated three times. The final elution was performed by adding $200 \mu \mathrm{L}$ of Tris buffer $(50 \mathrm{mM}, \mathrm{pH} 7.0)$ containing 1 $\mathrm{mM}$ dithiothreitol and $15 \mathrm{mM}$ reduced glutathione. The purity of the proteins was then monitored by sodium dodecyl sulfatePAGE.

Screening of Variants toward Acceptor Substrates. Storage microplates containing the neutral-drift library were thawed and replicated to inoculate starter culture in 96-well microplates containing in each well $200 \mu \mathrm{L}$ of $2 \mathrm{XYT}$ medium supplemented with $100 \mu \mathrm{g} \cdot \mathrm{mL}^{-1}$ ampicillin. After growth for $12 \mathrm{~h}$ at $30{ }^{\circ} \mathrm{C}(700 \mathrm{rpm})$, plates were duplicated four times into 96-Deep Well plates containing in each well $1 \mathrm{~mL}$ of ZYM-5052 auto-inducible medium supplemented with $100 \mu \mathrm{g}$. $\mathrm{mL}^{-1}$ ampicillin and then grown for $24 \mathrm{~h}$ at $30^{\circ} \mathrm{C}(700 \mathrm{rpm})$. The plates were then centrifuged $\left(20 \mathrm{~min}, 3000 \mathrm{~g}, 4{ }^{\circ} \mathrm{C}\right)$, and the supernatants were removed. The cell pellets were resuspended in $200 \mu \mathrm{L}$ of PBS $2 \mathrm{X}$ ( $\mathrm{pH} 7.3$, containing lysozyme $0.5 \mathrm{mg} / \mathrm{mL}$ and $1.5 \mathrm{U}$ of deoxyribonuclease I), followed by freezing at $-80{ }^{\circ} \mathrm{C}$ for $8-12 \mathrm{~h}$. Next, $100 \mu \mathrm{L}$ of enzymatic extract was transferred into a new microplate, and $50 \mu \mathrm{L}$ of sucrose was added as well as $50 \mu \mathrm{L}$ of acceptors. Sucrose:acceptor ratios were 1:1 for dulcitol (146:146 mM) and methyl- $\alpha$-L-rhamnopyranoside $(73: 73 \mathrm{mM})$ and 1:2 for xylitol (146:292 $\mathrm{mM})$ and myo-inositol (146:292 mM). Reactions were carried out for $24 \mathrm{~h}$ at $30{ }^{\circ} \mathrm{C}$, inactivated by heating at $95{ }^{\circ} \mathrm{C}$, and centrifuged $(3000 \mathrm{~g}, 20 \mathrm{~min})$. The acceptor reaction media were analyzed by direct injection mass spectrometry (MSQ Plus, Thermo Scientific) for methyl- $\alpha$-Lrhamnopyranoside and by high-pressure liquid chromatography (HPLC) analysis using a Dionex P 680 series pump, a Shodex RI 101 series refractometer, and an HTC PAL autosampler for other acceptors. HPLC analyses were performed on an HPX-87C column $(300 \mathrm{~mm} \times 7.8 \mathrm{~mm}$, Biorad) maintained at $65{ }^{\circ} \mathrm{C}$ using ultrapure water as eluent at a flow of $0.6 \mathrm{~mL} / \mathrm{min}$ for dulcitol and xylitol and with an HPX$87 \mathrm{~K}$ column $(300 \mathrm{~mm} \times 7.8 \mathrm{~mm}$, Biorad $)$ maintained at $65^{\circ} \mathrm{C}$ using a mixture of ultrapure water and acetonitrile (93.5:6.5\%) as eluent for myo-inositol. The acceptor conversion was calculated as follows: Conversion degree $=\left([\right.$ Acceptor $] t_{0}-$ $[$ Acceptor $\left.] t_{\mathrm{f}}\right) /[$ Acceptor $] t_{0}$, where [Acceptor] represents the molar acceptor concentration at $t_{\mathrm{f}}$, the final reaction time, and $t_{0}$, the reaction start time estimated with a negative control without enzyme or with the inactive amylosucrase variant E328Q.

Purification of Recombinant Enzymes. Variant 7945E5 was purified alongside WT amylosucrase. Production and purification were performed as previously described. ${ }^{43-45}$ Molecular weights of WT amylosucrase (71491.42 $\mathrm{g} \cdot \mathrm{mol}^{-1}$ ) and variant 7945E5 $\left(71542.47 \mathrm{~g} \cdot \mathrm{mol}^{-1}\right)$ were determined using ProtParam tool on ExPASy portal (web.expasy.org/ protparam/).

Activity Assays. Activities toward sucrose were determined by transferring $50 \mu \mathrm{L}$ of the crude enzymatic extracts into a microplate with $50 \mu \mathrm{L}$ of sucrose (final concentration 146 $\mathrm{mM}$ ) and incubating for $2 \mathrm{~h}$ at $30^{\circ} \mathrm{C}$. The reaction was stopped by adding $100 \mu \mathrm{L}$ of 3,5-dinitrosalicylic acid followed by heating at $95{ }^{\circ} \mathrm{C}$ for $10 \mathrm{~min}$, and the concentrations of released reducing sugars were determined by measuring the absorbance at $540 \mathrm{~nm}$ with a Sunrise spectrophotometer. Reactions were performed in triplicate to estimate the variability of the experiment. Relative activities were calculated with respect to the optical density of the culture (at $600 \mathrm{~nm}$ ) and were normalized to the parental value calculated from 56 full repeats (i.e., 56 cultures of $1 \mathrm{~mL}$ in 96-Deep Well plates).

Activities toward $p$-nitrophenyl- $\alpha$-D-glucopyranoside were determined by transferring $50 \mu \mathrm{L}$ of the purified enzymes into a microplate with $50 \mu \mathrm{L}$ of $p$-nitrophenyl- $\alpha$-D-glucopyranoside (final concentration $15 \mathrm{mM}$ ) after incubating for $15 \mathrm{~h}$ at $30^{\circ} \mathrm{C}$. The conversion of $p$-nitrophenyl- $\alpha$-D-glucopyranoside was determined by measuring the absorbance of $p$-nitrophenoxide released at $405 \mathrm{~nm}$ with a Sunrise spectrophotometer. Relative activities were calculated with respect to the optical density of the cultures and were normalized to the parental value calculated from 20 full repeats.

High-throughput screening experiments were performed using equipment from the ICEO facility (Laboratoire d'Ingénierie des Systèmes Biologiques et des Procédés (LISBP), Toulouse, France).

Thermostability of Enzymes. The melting points $\left(T_{\mathrm{m}}\right)$ of GST-fused amylosucrase variants were recorded in triplicate experiments by DSF. 215 randomly chosen variants were purified using the microplate purification protocol described previously. ${ }^{35}$ A mix of $19 \mu \mathrm{L}$ of enzyme and $1 \mu \mathrm{L}$ of Syproorange (5X final) (Invitrogen, Paisley, UK) was incubated using a temperature gradient ranging from 25 to $80{ }^{\circ} \mathrm{C}$ with a $0.3^{\circ} \mathrm{C}$ increment. The thermal transition was monitored with a RTQ-PCR CFX96 Real-Time System (Biorad, Marnes-laCoquette, France). The melting temperatures were determined as the maximums of the first derivative for each temperaturefluorescence curve and averaged, and the standard deviation for each $T_{\mathrm{m}}$ was determined.

Circular dichroism spectra of recombinant $N p A S$ and 7945E5 purified enzymes were recorded on a JASCO J815 spectropolarimeter equipped with a Peltier cell temperature controller. $T_{\mathrm{m}}$ values were obtained by heating the samples (enzyme $2 \mu \mathrm{M}$ in $50 \mathrm{mM}$ Tris, $\mathrm{pH} 7.0,150 \mathrm{mM} \mathrm{NaCl}, 1 \mathrm{mM}$ DTT, $1 \mathrm{mM} \mathrm{EDTA)} \mathrm{at} 1{ }^{\circ} \mathrm{C} \cdot \mathrm{min}^{-1}$ and recording the ellipticity at 220 and $240 \mathrm{~nm}$ from 25 to $80{ }^{\circ} \mathrm{C}$ with delays of 
30 s. The melting temperatures were determined by fitting analyses using SigmaPlot 10.0.

Structure Determination. Crystallization Conditions. Variant 7945E5 was crystallized using conditions described previously. ${ }^{39}$ Experiments were carried out in 24-well plates at $12{ }^{\circ} \mathrm{C}$ using the hanging drop vapor diffusion method. One volume of protein at $10 \mathrm{mg} \cdot \mathrm{mL}^{-1}$ (in Tris $50 \mathrm{mM}, \mathrm{NaCl} 150$ mM, EDTA $1 \mathrm{mM}$, DTT $1 \mathrm{mM}, \mathrm{pH} 7.3$ ) was mixed with one volume of precipitant solution (PEG 6000 at $25,30,35 \%$, or $40 \%$ (w/v), 0.1 M HEPES at $\mathrm{pH} 6.8,7.0,7.3,7.6,7.9$, or 8.2). Platelet crystals appeared after 1 week. The best crystallization conditions were obtained with PEG 6000 at $30 \%$ (w/v) and 0.1 M HEPES $\mathrm{pH}$ 7.9.

Data Collection and Structure Determination. X-ray experiments were carried out at $100 \mathrm{~K}$. Prior to flash cooling, crystals of variant 7945E5 were soaked for $3 \mathrm{~min}$ in the reservoir solution supplemented with $100 \mathrm{mM}$ methyl- $\alpha$-Lrhamnopyranoside and $100 \mathrm{mM}$ sucrose. Diffraction data sets were collected to a maximum resolution of $1.60 \AA$ on beamline ID29 at the European Synchrotron Radiation facility (ESRF, Grenoble, France). Diffracted intensities were integrated and scaled using $\mathrm{XDS},{ }^{46}$ and $5 \%$ of the scaled amplitudes were randomly selected and excluded from the refinement procedure. Crystals of variant 7945E5 belong to orthorhombic space group $\mathrm{P} 22_{1} 2_{1}$ with one molecule per asymmetric unit giving a Matthews coefficient of $2.4 \AA^{3} / \mathrm{Da}$. Data collection statistics are given in Table S2.

Model Building and Refinement. Structure refinement was performed using the structure of parental NpAS (PDB code: 1G5A) as an initial model and refmac5 from CCP4 GUI. ${ }^{47}$ The model was built manually in SigmaA weighted electron density maps using COOT. ${ }^{48}$ Water molecules were automatically assigned, and ligand molecules were fitted manually into residual maps. The final model was refined to final $R$ and $R_{\text {free }}$ of $14.8 \%$ and $18.0 \%$, respectively. Refinement statistics are given in Table 2. Coordinates of the structure of variant 7945E5 have been deposited at the Protein Data Bank (PDB code: $5 \mathrm{~N} 6 \mathrm{~V})$.

\section{ASSOCIATED CONTENT}

\section{S Supporting Information}

The Supporting Information is available free of charge on the ACS Publications website at DOI: 10.1021/acscatal.8b03609.

Supporting tables and figures showing details of variant analysis, crystallographic data collection, and structural analysis of variant 7945E5 (PDF)

\section{AUTHOR INFORMATION}

\section{Corresponding Authors}

*E-mail: isabelle.andre@insa-toulouse.fr.

*E-mail: remaud@insa-toulouse.fr.

\section{ORCID $\odot$}

Isabelle André: 0000-0001-6280-4109

Magali Remaud-Siméon: 0000-0002-2658-672X

\section{Author Contributions}

${ }^{\S}$ D.D. and A.V. contributed equally to this work.

\section{Notes}

The authors declare no competing financial interest.

\section{ACKNOWLEDGMENTS}

This work was supported by the French National Research Agency (ANR Project GLUCODESIGN, ANR-08-PCVI-00202). D.D. and A.V. were supported by Ph.D. grants from the French Ministry of Research. The authors are grateful to S. Bozonnet and S. Pizzut-Serin for assistance when using the enzyme screening equipment of the ICEO facility (located in the LISBP and part of the Integrated Screening Platform of Toulouse PICT, IBiSA). They also thank members of the biophysical facility from IPBS (PICT, IBiSA) for providing access to DSF and crystallography equipment. The authors thank the European Synchrotron Radiation Facility (ESRF) at Grenoble (France), particularly the beamline ID29 staff. The authors would like to thank A.-M. Besançon, S. Cantos, and N. Monties for technical assistance. We are also grateful to L. A. Mulard for the precious gift of the disaccharides used as standards. The authors are grateful to Sean Devenish for careful and meticulous reading of the manuscript.

\section{REFERENCES}

(1) Peisajovich, S. G.; Tawfik, D. S. Protein Engineers Turned Evolutionists. Nat. Methods 2007, 4, 991-994.

(2) Stemmer, W. P. DNA Shuffling by Random Fragmentation and Reassembly: In Vitro Recombination for Molecular Evolution. Proc. Natl. Acad. Sci. U. S. A. 1994, 91, 10747-10751.

(3) Zhao, H.; Giver, L.; Shao, Z.; Affholter, J. A.; Arnold, F. H. Molecular Evolution by Staggered Extension Process (StEP) in Vitro Recombination. Nat. Biotechnol. 1998, 16, 258-261.

(4) Bornscheuer, U. T.; Huisman, G. W.; Kazlauskas, R. J.; Lutz, S.; Moore, J. C.; Robins, K. Engineering the Third Wave of Biocatalysis. Nature 2012, 485, 185-194.

(5) Dalby, P. A. Strategy and Success for the Directed Evolution of Enzymes. Curr. Opin. Struct. Biol. 2011, 21, 473-480.

(6) Davids, T.; Schmidt, M.; Böttcher, D.; Bornscheuer, U. T. Strategies for the Discovery and Engineering of Enzymes for Biocatalysis. Curr. Opin. Chem. Biol. 2013, 17, 215-220.

(7) Turner, N. J. Directed Evolution of Enzymes for Applied Biocatalysis. Trends Biotechnol. 2003, 21, 474-478.

(8) Longwell, C. K.; Labanieh, L.; Cochran, J. R. High-Throughput Screening Technologies for Enzyme Engineering. Curr. Opin. Biotechnol. 2017, 48, 196-202.

(9) Goldsmith, M.; Tawfik, D. S. Directed Enzyme Evolution: Beyond the Low-Hanging Fruit. Curr. Opin. Struct. Biol. 2012, 22, 406-412.

(10) Reetz, M. T.; Bocola, M.; Carballeira, J. D.; Zha, D.; Vogel, A. Expanding the Range of Substrate Acceptance of Enzymes: Combinatorial Active-Site Saturation Test. Angew. Chem. 2005, 117, 4264-4268.

(11) Jochens, H.; Bornscheuer, U. T. Natural Diversity to Guide Focused Directed Evolution. ChemBioChem 2010, 11, 1861-1866.

(12) Kimura, M. The Neutral Theory of Molecular Evolution; Cambridge University Press: Cambridge, 1983.

(13) Bershtein, S.; Goldin, K.; Tawfik, D. S. Intense Neutral Drifts Yield Robust and Evolvable Consensus Proteins. J. Mol. Biol. 2008, 379, 1029-1044.

(14) Bloom, J. D.; Romero, P. A.; Lu, Z.; Arnold, F. H. Neutral Genetic Drift Can Alter Promiscuous Protein Functions, Potentially Aiding Functional Evolution. Biol. Direct 2007, 2, 17.

(15) Aharoni, A.; Gaidukov, L.; Khersonsky, O.; Gould, S. M.; Roodveldt, C.; Tawfik, D. S. The "evolvability" of Promiscuous Protein Functions. Nat. Genet. 2005, 37, 73-76.

(16) Amitai, G.; Gupta, R. D.; Tawfik, D. S. Latent Evolutionary Potentials under the Neutral Mutational Drift of an Enzyme. HFSP J. 2007, 1, 67-78.

(17) Wroe, R.; Chan, H. S.; Bornberg-Bauer, E. A Structural Model of Latent Evolutionary Potentials Underlying Neutral Networks in Proteins. HFSP J. 2007, 1, 79-87. 
(18) Gupta, R. D.; Tawfik, D. S. Directed Enzyme Evolution via Small and Effective Neutral Drift Libraries. Nat. Methods 2008, 5, 939-942.

(19) Smith, W. S.; Hale, J. R.; Neylon, C. Applying Neutral Drift to the Directed Molecular Evolution of a $\beta$-Glucuronidase into a $\beta$ Galactosidase: Two Different Evolutionary Pathways Lead to the Same Variant. BMC Res. Notes 2011, 4, 138.

(20) Romanini, D. W.; Peralta-Yahya, P.; Mondol, V.; Cornish, V. W. A Heritable Recombination System for Synthetic Darwinian Evolution in Yeast. ACS Synth. Biol. 2012, 1, 602-609.

(21) Kaltenbach, M.; Tokuriki, N. Generation of Effective Libraries by Neutral Drift. In Directed Evolution Library Creation; Gillam, E. M. J., Copp, J. N., Ackerley, D., Eds.; Methods in Molecular Biology; Springer: New York, 2014; pp 69-81, DOI: 10.1007/978-1-49391053-3 5.

(22) Coutinho, P.; Henrissat, B. Carbohydrate-Active Enzymes: An Integrated Database Approach Server; 1999.

(23) Moulis, C.; André, I.; Remaud-Simeon, M. GH13 Amylosucrases and GH70 Branching Sucrases, Atypical Enzymes in Their Respective Families. Cell. Mol. Life Sci. 2016, 73, 2661-2679.

(24) André, I.; Potocki-Véronèse, G.; Morel, S.; Monsan, P.; Remaud-Siméon, M. Sucrose-Utilizing Transglucosidases for Biocatalysis. In Carbohydrates in Sustainable Development I; Rauter, A. P., Vogel, P., Queneau, Y., Eds.; Topics in Current Chemistry; Springer: Berlin/Heidelberg, 2010; pp 25-48. https://doi.org/10.1007/128_ 201052.

(25) Monsan, P.; Remaud-Siméon, M.; André, I. Transglucosidases as Efficient Tools for Oligosaccharide and Glucoconjugate Synthesis. Curr. Opin. Microbiol. 2010, 13, 293-300.

(26) Daudé, D.; Champion, E.; Morel, S.; Guieysse, D.; RemaudSiméon, M.; André, I. Probing Substrate Promiscuity of Amylosucrase from Neisseria Polysaccharea. ChemCatChem 2013, 5, 2288-2295.

(27) Champion, E.; André, I.; Moulis, C.; Boutet, J.; Descroix, K.; Morel, S.; Monsan, P.; Mulard, L. A.; Remaud-Siméon, M. Design of $\alpha$-Transglucosidases of Controlled Specificity for Programmed Chemoenzymatic Synthesis of Antigenic Oligosaccharides. J. Am. Chem. Soc. 2009, 131, 7379-7389.

(28) Champion, E.; Guérin, F.; Moulis, C.; Barbe, S.; Tran, T. H.; Morel, S.; Descroix, K.; Monsan, P.; Mourey, L.; Mulard, L. A.; Tranier, S.; Remaud-Siméon, M.; André, I. Applying Pairwise Combinations of Amino Acid Mutations for Sorting Out Highly Efficient Glucosylation Tools for Chemo-Enzymatic Synthesis of Bacterial Oligosaccharides. J. Am. Chem. Soc. 2012, 134, 1867718688 .

(29) Verges, A.; Cambon, E.; Barbe, S.; Salamone, S.; Le Guen, Y.; Moulis, C.; Mulard, L. A.; Remaud-Siméon, M.; André, I. ComputerAided Engineering of a Transglycosylase for the Glucosylation of an Unnatural Disaccharide of Relevance for Bacterial Antigen Synthesis. ACS Catal. 2015, 5, 1186-1198.

(30) Vergès, A.; Cambon, E.; Barbe, S.; Moulis, C.; Remaud-Siméon, M.; André, I. Novel Product Specificity toward Erlose and Panose Exhibited by Multisite Engineered Mutants of Amylosucrase. Protein Sci. 2017, 26, 566-577.

(31) Vergès, A.; Barbe, S.; Cambon, E.; Moulis, C.; Tranier, S.; Remaud-Siméon, M.; André, I. Engineering of Anp Efficient Mutant of Neisseria Polysaccharea Amylosucrase for the Synthesis of Controlled Size Maltooligosaccharides. Carbohydr. Polym. 2017, 173, 403-411.

(32) Malbert, Y.; Pizzut-Serin, S.; Massou, S.; Cambon, E.; Laguerre, S.; Monsan, P.; Lefoulon, F.; Morel, S.; André, I.; Remaud-Simeon, M. Extending the Structural Diversity of $\alpha$-Flavonoid Glycosides with Engineered Glucansucrases. Chem CatChem 2014, 6, 2282-2291.

(33) Champion, E.; Moulis, C.; Morel, S.; Mulard, L. A.; Monsan, P.; Remaud-Siméon, M.; André, I. A PH-Based High-Throughput Screening of Sucrose-Utilizing Transglucosidases for the Development of Enzymatic Glucosylation Tools. ChemCatChem 2010, 2, 969-975.
(34) Okada, G.; Hehre, E. J. De Novo Synthesis of Glycosidic Linkages by Glycosylases: Utilization of $\alpha$-d-Glucopyranosyl Fluoride by Amylosucrase. Carbohydr. Res. 1973, 26, 240-243.

(35) Daudé, D.; Topham, C. M.; Remaud-Siméon, M.; André, I. Probing Impact of Active Site Residue Mutations on Stability and Activity of Neisseria Polysaccharea Amylosucrase: Probing Impact of Active Site Residue Mutations. Protein Sci. 2013, 22, 1754-1765.

(36) Skov, L. K.; Mirza, O.; Henriksen, A.; De Montalk, G. P.; Remaud-Simeon, M.; Sarçabal, P.; Willemot, R.-M.; Monsan, P.; Gajhede, M. Amylosucrase, a Glucan-Synthesizing Enzyme from the $\alpha$-Amylase Family. J. Biol. Chem. 2001, 276, 25273-25278.

(37) Perepelov, A. V.; Shevelev, S. D.; Liu, B.; Senchenkova, S. N.; Shashkov, A. S.; Feng, L.; Knirel, Y. A.; Wang, L. Structures of the OAntigens of Escherichia Coli O13, O129, and O135 Related to the OAntigens of Shigella Flexneri. Carbohydr. Res. 2010, 345, 1594-1599.

(38) Albenne, C.; Potocki de Montalk, G.; Monsan, P.; Skov, L. K.; Mirza, O.; Gajhede, M.; Remaud-Simeon, M. Site-Directed Mutagenesis of Key Amino Acids in the Active Site of Amylosucrase from Neisseria Polysaccharea. Biol., Bratisl. 2002, 57 (Suppl 11), 119-128.

(39) Skov, L. K.; Mirza, O.; Sprogøe, D.; van der Veen, B. A.; Remaud-Simeon, M.; Albenne, C.; Monsan, P.; Gajhede, M. Crystal Structure of the Glu328Gln Mutant of Neisseria Polysaccharea Amylosucrase in Complex with Sucrose and Maltoheptaose. Biocatal. Biotransform. 2006, 24, 99-105.

(40) Tokuriki, N.; Tawfik, D. S. Stability Effects of Mutations and Protein Evolvability. Curr. Opin. Struct. Biol. 2009, 19, 596-604.

(41) Tokuriki, N.; Stricher, F.; Serrano, L.; Tawfik, D. S. How Protein Stability and New Functions Trade Off. PLoS Comput. Biol. 2008, 4, No. e1000002.

(42) Champion, E.; André, I.; Mulard, L. A.; Monsan, P.; RemaudSiméon, M.; Morel, S. Synthesis of L-Rhamnose and N -Acetyl-DGlucosamine Derivatives Entering in the Composition of Bacterial Polysaccharides by Use of Glucansucrases. J. Carbohydr. Chem. 2009, $28,142-160$.

(43) Emond, S.; Mondeil, S.; Jaziri, K.; André, I.; Monsan, P.; Remaud-Siméon, M.; Potocki-Véronèse, G. Cloning, Purification and Characterization of a Thermostable Amylosucrase from Deinococcus Geothermalis. FEMS Microbiol. Lett. 2008, 285, 25-32.

(44) De Montalk, G. P.; Remaud-Simeon, M.; Willemot, R. M.; Planchot, V.; Monsan, P. Sequence Analysis of the Gene Encoding Amylosucrase from Neisseria Polysaccharea and Characterization of the Recombinant Enzyme. J. Bacteriol. 1999, 181, 375-381.

(45) Pizzut-Serin, S.; Potocki-Véronèse, G.; van der Veen, B. A.; Albenne, C.; Monsan, P.; Remaud-Simeon, M. Characterisation of a Novel Amylosucrase from Deinococcus Radiodurans. FEBS Lett. 2005, 579, 1405-1410.

(46) Kabsch, W. Automatic Processing of Rotation Diffraction Data from Crystals of Initially Unknown Symmetry and Cell Constants. J. Appl. Crystallogr. 1993, 26, 795-800.

(47) Murshudov, G. N.; Vagin, A. A.; Dodson, E. J. Refinement of Macromolecular Structures by the Maximum-Likelihood Method. Acta Crystallogr., Sect. D: Biol. Crystallogr. 1997, 53, 240-255.

(48) Emsley, P.; Cowtan, K. Coot: Model-Building Tools for Molecular Graphics. Acta Crystallogr., Sect. D: Biol. Crystallogr. 2004, 60, 2126-2132. 